\title{
Development of an artificial placenta for support of premature infants: narrative review of the history, recent milestones, and future innovation
}

\author{
Brian P. Fallon ${ }^{1}$, George B. Mychaliska ${ }^{2}$ \\ ${ }^{1}$ Department of Surgery, University of Michigan, Michigan Medicine, Ann Arbor, Michigan, USA; ${ }^{2}$ Department of Surgery, Section of Pediatric \\ Surgery, Fetal Diagnosis and Treatment Center, University of Michigan, Michigan Medicine, Ann Arbor, Michigan, USA \\ Contributions: (I) Conception and design: All authors; (II) Administrative support: All authors; (III) Provision of study materials or patients: All \\ authors; (IV) Collection and assembly of data: All authors; (V) Data analysis and interpretation: All authors; (VI) Manuscript writing: All authors; (VII) \\ Final approval of manuscript: All authors. \\ Correspondence to: Brian P. Fallon, MD. ECLS Laboratory, Department of Surgery, Michigan Medicine, B560 MSRB II/SPC 5686, 1150 W. Medical \\ Center Drive, Ann Arbor, MI 48109, USA. Email: bfallon@med.umich.edu.
}

\begin{abstract}
Over 50 years ago, visionary researchers began work on an extracorporeal artificial placenta to support premature infants. Despite rudimentary technology and incomplete understanding of fetal physiology, these pioneering scientists laid the foundation for future work. The research was episodic, as medical advances improved outcomes of premature infants and extracorporeal life support (ECLS) was introduced for the treatment of term and near-term infants with respiratory or cardiac failure. Despite ongoing medical advances, extremely premature infants continue to suffer a disproportionate burden of mortality and morbidity due to organ immaturity and unintended iatrogenic consequences of medical treatment. With advancing technology and innovative approaches, there has been a resurgence of interest in developing an artificial placenta to further diminish the mortality and morbidity of prematurity. Two related but distinct platforms have emerged to support premature infants by recreating fetal physiology: a system based on arteriovenous (AV) ECLS and one based on veno-venous (VV) ECLS. The AV-ECLS approach utilizes only the umbilical vessels for cannulation. It requires immediate transition of the infant at the time of birth to a fluid-filled artificial womb to prevent umbilical vessel spasm and avoid gas ventilation. In contradistinction, the VV-ECLS approach utilizes the umbilical vein and the internal jugular vein. It would be applied after birth to infants failing maximal medical therapy or preemptively if risk stratified for high mortality and morbidity. Animal studies are promising, demonstrating prolonged support and ongoing organ development in both systems. The milestones for clinical translation are currently being evaluated.
\end{abstract}

Keywords: Artificial placenta; artificial womb; extracorporeal membrane oxygenation (ECMO); extracorporeal support; prematurity

Submitted May 04, 2020. Accepted for publication Jul 30, 2020.

doi: $10.21037 /$ tp-20-136

View this article at: http://dx.doi.org/10.21037/tp-20-136

\section{Introduction}

One in 10 infants in the United States is born premature (1). Though recent advances in the care of premature newborns has dramatically improved outcomes, their mortality rate is still 17 times higher than full-term newborns, with 1 in 3 infant deaths in the United States due to complications prematurity (1). A novel solution for these patients is an artificial placenta, which recreates fetal physiology to promote normal organ development. In the last decade, the artificial placenta has progressed from relative obscurity to a well-developed technology poised for clinical translation in the near future. As more laboratories invest in the 
Table 1 Incidence of major morbidities among ELGANs (5)

\begin{tabular}{lc}
\hline Morbidity & $\begin{array}{c}\% \text { of } \\
\text { ELGANs }\end{array}$ \\
\hline Pulmonary & 43 \\
Bronchopulmonary dysplasia (BPD) & \\
Neurologic & 16 \\
Severe intraventricular hemorrhage (IVH) (grade 3-4) & 5 \\
Periventricular leukomalacia (PVL) & 12 \\
Gastrointestinal & \\
Necrotizing enterocolitis (NEC) & 59 \\
Ophthalmologic & 12 \\
Retinopathy of prematurity (ROP) diagnosed & \\
Intervention/surgical treatment for ROP & 2 \\
Immunologic & 36 \\
Sepsis, early-onset & \\
Sepsis, late-onset &
\end{tabular}

ELGANs, extremely low gestational age newborns.

development of an artificial placenta system, the pace of innovation is accelerating. Nevertheless, a number of key milestones must be accomplished before it can be trialed in humans. The purpose of this article is to review the history of the artificial placenta, summarize the myriad advancements of recent years, and to describe the key challenges researchers must address prior to clinical translation. We present the following article in accordance with the narrative review reporting checklist (available at http://dx.doi.org/10.21037/tp-20-136).

\section{Prematurity: epidemiology, morbidity, and mortality}

Prematurity remains a major unsolved public health problem both in the United States and worldwide. Over 375,000 infants are born premature [less than 37 weeks estimated gestational age (EGA)] in the United States each year, accounting for $10 \%$ of all births (1). These infants are at an increased risk of morbidity and mortality compared to infants born full term. This risk increases with decreasing gestational age, with a disproportionate burden of morbidity and mortality for extremely low gestational age newborns (ELGANs), defined as neonates born at less than 28 weeks EGA. Infants born at less than 37 weeks are at $3.4 \%$ risk of dying before the age of 1 year compared to $0.2 \%$ for fullterm infants. This mortality risk climbs to $38.4 \%$ for the 25,000 ELGANs (1). This makes prematurity the second leading cause of infant death in the United States.

Given the scope of the problem, there has been a concerted effort to improve outcomes for prematurity. Studies have shown that outcomes have improved for ELGANs, with absolute mortality decreases from 2 to $13 \%$ in the past two decades $(2,3)$. These improvements in critical care for extremely premature newborn have caused the limit of viability to gradually shift downward. One-year survival rates for newborns at 22 and 23 weeks has increased to as high as $36 \%$ and $64 \%$, respectively, in Japanese studies (4). Nevertheless, only $36 \%$ of ELGANs survive to discharge without a major morbidity (5). Even fewer-22\%—-survive to adulthood without a major morbidity (6). This presents a great opportunity to improve the care we provide to this vulnerable population.

The poor outcomes for this patient population stem from two interrelated factors: organ immaturity and the unintended iatrogenic consequences of conventional medical treatments. Lung immaturity is a major driver for many of the complications of prematurity (Table 1). The positive-pressure ventilation required by many of these infants has been associated with negative physiologic effects on the lung, including decreased surfactant production (7), increased pulmonary vascular resistance (8), and activation of local and systemic inflammatory responses (7). Cardiac output is also negatively affected due to the decreased pulmonary blood flow (9). The associated elevation in intrathoracic and thus intracranial pressure has been associated with an increased risk of intraventricular hemorrhage (10). Lastly, the high fraction of inspired oxygen $\left(\mathrm{FiO}_{2}\right)$ that these patients require is a major contributor to retinopathy of prematurity (11).

\section{Advances in care of the premature newborn}

A greater appreciation for the deleterious effects of these supportive measures has driven many advances in the care of premature neonates. Primary among them is the shift toward gentler respiratory support strategies. This has resulted in improvements in overall and bronchopulmonary dysplasia (BPD)-specific outcomes. These include avoiding endotracheal intubation in favor of nasal continuous positive airway pressure (CPAP) to the extent possible (12-14). The use of nasal intermittent positive pressure ventilation (NIPPV) may further help prevent intubation, 
though effects of this ventilation strategy on overall survival and long-term outcomes are not yet known (15).

When endotracheal intubation is necessary, gentler ventilation strategies have been associated with improved outcomes. These include using the lowest possible ventilator settings, permissive hypercapnia $\left(\mathrm{PaCO}_{2} 45-60 \mathrm{mmHg}\right)$, and early extubation when possible (16-21). The ideal target for oxygen saturation for ELGANs remains controversial despite being well studied (22-25). Generally, no difference has been found between a restrictive $\left(\mathrm{SpO}_{2}, 85-89 \%\right)$ and a liberal $\left(\mathrm{SpO}_{2}, 91-95 \%\right)$ saturation target in the composite outcome of death or major disability. Neurodevelopmental outcomes have also been similar between the two strategies. A restrictive strategy has been associated with lower rates of ROP $(22,25)$ and lower need for supplemental oxygen at 36 weeks post-conceptual age (25), which has been used by some as a definition for BPD. This is counterbalanced by evidence of higher rates of mortality $(22,24,25)$, necrotizing enterocolitis (NEC) $(22,23,25)$, and patent ductus arteriosus requiring surgical ligation (25) with the restrictive oxygen target.

A variety of ventilation modes have been evaluated to limit ventilator-induced lung injury for ELGANs. Volumetargeted ventilation, which may limit the overdistension of the lung ("volutrauma"), has been associated with a lower incidence of BPD and decreased mortality compared to pressure-limited ventilation (26). Neurally adjusted ventilator assistance (NAVA) has been developed recently as a more natural, gentler method of ventilation that delivers breaths in synchrony with the electrical activity of the patient's diaphragm. It can be used with both noninvasive and invasive mechanical ventilation. Early studies in premature infants suggest that both NAVA and noninvasive NAVA facilitate the use of lower ventilator settings compared to traditional support modes $(27,28)$; however, definitive data on improved patient outcomes is currently lacking. High-frequency oscillatory ventilation (HFOV) has been frequently studied as an alternative to conventional ventilation for premature neonates with respiratory distress syndrome (RDS). These trials consistently show no benefit of HFOV over conventional ventilation in terms of mortality or neurologic outcomes (29); however, some trials have shown a decrease in the rate of chronic lung disease in those patients managed with $\mathrm{HFOV}$ (30).

Antenatal steroids have been the standard of care for decades for any pregnant woman at 23-34 weeks EGA at risk of delivery (31). Their use has been associated with decreased rates of RDS and improved survival, as well as NEC, intraventricular hemorrhage, and sepsis (32). Surfactant use has the potential to provide benefits when used selectively in patients receiving CPAP at the time of delivery (33). Evidence is currently mixed on the true riskbenefit profile of postnatal systemic steroids, but recent studies have suggested that endotracheal administration of budesonide along with surfactant may reduce the risk of BPD without significant adverse outcomes (34).

Some premature newborns will benefit from these advancements and survive with limited morbidity. Nevertheless, the sickest of premature newborns who are failing the above methods currently are still without successful treatment options. Therefore, a paradigm shift in the treatment of extreme prematurity is required to make a significant impact on morbidity and mortality.

\section{History of the artificial placenta}

A radical paradigm shift in the treatment of prematurity would be to recreate the intrauterine environment with an extracorporeal artificial placenta (AP). Interestingly, research into the artificial placenta began shortly after the advent of extracorporeal circulation for cardiac surgery. In 1953, Dr. Gibbon performed the first openheart operation on cardiopulmonary bypass. It was not long before investigators were exploring new uses for this technology (35). The premature fetus was perhaps an obvious target for translation, as it naturally develops with placental extracorporeal circulation via the umbilical cord. In 1958, Westin cannulated the umbilical vessels of previable human fetuses and enclosed them into an airtight chamber filled with hypothermic isotonic glucose. Umbilical artery drainage entered an Archimedean screw that served as a pump by raising the blood to $40 \mathrm{~cm}$ as well as an oxygenator that exposed the blood to a countercurrent of oxygen. He succeeded in supporting 7 fetuses weighing 200-375 g for up to 12 hours (36). Lawn and McCance supported fetal pigs with pumpless AV support through the umbilical vessels for up to 7 hours, achieving flows of $18-63 \mathrm{~mL} / \mathrm{kg} / \mathrm{min}$ (37-39). Alexander provided pumpless AV support to sheep fetuses for up to 19 hours (40). Callaghan and colleagues conducted a series of experiments that ultimately led to survival of premature lambs for 165 minutes of AP support (41-43). These early studies typically used a blood reservoir elevated above the fetus to facilitate reinfusion and had priming volumes up to $1.5 \mathrm{~L}$. The greatest success in these early groups was achieved by Zapol and colleagues, who supported a sheep fetus for 
55 hours and 4 others for over 20 hours with an AV circuit with a pump via umbilical cannulation (44). These early studies were groundbreaking in their exploration of extracorporeal circulation in a premature model. They served as the cornerstone for subsequent research in both extracorporeal membrane oxygenation (ECMO) and the AP. Nevertheless, their success was limited by the technology available at the time-thick-walled metal cannulae, rudimentary bubble oxygenators, and high-pressure roller pumps. This also limited their investigation into fetal blood flow, gas exchange, cerebral blood flow, and fetal physiology.

The interest in the artificial placenta diminished in the 1970s as major advances were made in the care of premature neonates, including exogenous surfactant, prenatal steroids to stimulate lung development, advanced modes of ventilation, and the clinical use of ECMO in term and nearterm neonates $(31,45-47)$.

\section{Neonatal ECMO}

Development of the artificial placenta would not be possible without the seminal advances in prolonged extracorporeal support ushered in by ECMO. In 1975, extracorporeal circulation for neonates was first successfully implemented clinically by Dr. Robert Bartlett to support a newborn girl suffering from meconium aspiration $(48,49)$. The first series of neonates supported on ECMO was published by Bartlett and colleagues in 1982 with a survival rate of $50 \%$ in 45 patients (50). Since that time, ECMO has been an effective therapy for near-term and term neonates in respiratory and cardiac failure. Neonates made up the vast majority of ECMO patients in the early years of ECMO. This trend has reversed in recent years, prompted both by a growth in adult ECMO starting in 2008 as well as a gradual decline in the number of neonatal cases. In 1990, neonatal cases made up $82 \%$ of all ECMO cases compared to $8.1 \%$ in 2016 (51). The largest drop in cases has been meconium aspiration syndrome (MAS), RDS, and sepsis, decreasing from a combined $61 \%$ to $21 \%$ of cases from 1990 to 2016. Though the absolute number of ECMO runs for patients with congenital diaphragmatic hernia $(\mathrm{CDH})$ and persistent pulmonary hypertension of the newborn have remained roughly stable since 1990 , those two indications now make up $50 \%$ of cases compared to $34 \%$ in 1990 . The primary driver behind this change in case mix has been the improvements in neonatal critical care, most notably advanced ventilator strategies, inhaled nitric oxide, and exogenous surfactant, as discussed previously (51).
Due to the risk of intracranial hemorrhage (ICH) and constraints on flow with smaller cannulas, the generally accepted empiric guidelines for ECMO remain $\geq 34$ weeks EGA and $\geq 2.0 \mathrm{~kg}$. However, there is a collective experience with 'preemie ECMO' with potentially higher but clinically acceptable rates of ICH and mortality. One study of the Extracorporeal Life Support Organization (ELSO) registry found no difference in ECMO-associated $\mathrm{ICH}$ rates between neonates born at 29-33 weeks EGA and those born at 34 weeks EGA (21\% vs. $17 \%, \mathrm{P}=0.195)$. Although the survival rate was lower ( $48 \%$ versus $58 \%$, respectively), these data demonstrate feasibility and acceptable survival for otherwise lethal respiratory and cardiac failure in premature infants (52).

The collective experience with neonatal and 'preemie ECMO' in terms of physiology and technology laid the foundation for the modern era of artificial placenta research. Decades of experience and research revealed the physiologic effects of prolonged extracorporeal support on all organ systems, which is critical to AP innovation and application. ECMO monitoring and critical-care algorithms have been adapted to address fetal physiology. Lastly, the many technological ECMO advances (low resistance oxygenators, circuits, cannulas, surface coatings and pumps) are used in novel ways to develop an artificial placenta to support premature infants.

\section{Resurgence of artificial placenta research}

Building upon the recent growth of neonatal ECMO and accompanying advancements in technology, in 1979, Griffith and colleagues performed a robust physiologic study of arteriovenous (AV) ECMO with umbilical cannulation to support premature lambs for 4-6 hours (53). His goal was not to develop an artificial placenta, but rather to develop an alternative perfusion strategy for neonates with respiratory distress, demonstrating a decline in pulmonary vascular resistance by delivering oxygenated blood directly to the pulmonary vasculature.

The next major phase in artificial placenta development was led by Dr. Yoshinori Kuwabara at the University of Tokyo during the 1980s. In 1987, they supported 14 premature goat fetuses with an AV circuit with a pump (54). The addition of a reservoir to their circuit resulted in up to 165 hours of support. The investigators noted high rates of cardiac failure among the animals. They further modified their circuit in 1989 and achieved up to 236 hours of support, though progressive circulatory depression was again evident (55). Subsequent studies by this group 
Table 2 Comparison of AV and VV-ECLS artificial placenta systems

\begin{tabular}{lcc}
\hline Characteristic & AV-ECLS & VV-ECLS \\
\hline Target population & EGA 22-24 weeks & EGA <28 weeks \\
Cannulation & During delivery & After failing ventilation \\
Drainage cannula & Umbilical artery (1 or 2) & Internal jugular vein \\
Reinfusion cannula & Umbilical vein & Umbilical vein \\
Circuit pump & Fetal heart & Mechanical pump \\
Airway management & Fluid-filled "biobag" & Intubated, fluid-filled lungs \\
\hline
\end{tabular}

$\mathrm{AV}$, arteriovenous; $\mathrm{V}$, veno-venous; ECLS, extracorporeal life support.

achieved survival up to 3 weeks $(56,57)$. Another Japanese group developed an $\mathrm{AV}$ perfusion system using a centrifugal pump. This provided support for up to 237 hours, but again the cause of death for all the animals was circulatory failure (58). These studies formed the foundation for much of the current AP research.

\section{Current AP systems}

There are several major research laboratories currently working on the development of an artificial placenta. Each system is unique, but all share features that can be considered defining characteristics of an artificial placenta:

(I) Extracorporeal circulation designed for ELGANs;

(II) Maintenance of fetal circulation;

(III) Fluid-filled lungs;

(IV) Vascular access entirely or partly through the umbilical vessels;

(V) Specialized environment for organ protection and ongoing development.

The similarities and differences between the two predominant configurations for an artificial placenta are summarized in Table 2.

\section{Pumpless AV-ECLS}

The extracorporeal life support (ECLS) Laboratory at the University of Michigan (UM) began work on the development of an artificial placenta in the early 2000s with an evaluation of the relationship between flow through an $\mathrm{AV}$ circuit and gas exchange in a rabbit model (59). This paved the way for the development of an AP using pumpless AV ECLS with a custom low-resistance oxygenator using transumbilical cannulation. The first series of near-term lambs (3.6-6.5 kg) was moderately successful, with 5 of 7 lambs surviving the 4-hour study period (60). Important information was learned about the feasibility of a pumpless, transumbilical AV circuit. All the animals developed progressive decline in cardiac function that resulted in hypotension, hypoxia, and a decrease in flows by $54 \%$ over the study period. This led the authors to conclude that a pumpless system, even when used with a low-resistance oxygenator, would be limited by cannula resistance and umbilical arterial spasm resulting in diminished flows and cardiac failure. This led us to conclude that, although a pumpless transumbilical AV mode is simple and attractive, it is in series with the systemic circulation, which puts additional strain on the heart that worsens in the presence of any degree of vasospasm.

More recently, significant advances have been made in the pumpless AV-ECLS AP system by the research team at Children's Hospital of Philadelphia (CHOP). They have developed the EXTra-uterine Environment for Neonatal Development (EXTEND) system using a pumpless AV circuit. They have evaluated three different cannulation strategies-carotid artery/jugular vein $(\mathrm{CA} / \mathrm{JV})$, carotid artery/umbilical vein, (CA/UV) and umbilical artery $(\times 2) /$ umbilical vein $(\mathrm{UA} / \mathrm{UV})$. In comparing the three strategies, they found that the $\mathrm{UA} / \mathrm{UV}$ approach resulted in successful placement of larger cannulae, longer circuit runs, higher weightadjusted circuit flows, and fewer flow interruptions (61). They did note a consistent gradual decline in weightadjusted flow over the course of the runs for which no clear cause could be identified. A subsequent study used echocardiography to identify increased heart strain in the first two weeks of support on EXTEND with return to baseline by the third week (62). They demonstrated four weeks of support with hemodynamic stability, maintenance of fetal circulation, adequate gas exchange, and evidence 
of fetal growth (63). They have made significant progress in mitigating umbilical vessel spasm by topical papaverine administration, atraumatic operative technique during cannulation, maintaining warmth, physiologic oxygen saturation of the umbilical venous inflow when initiating circuit flow and immediate transfer from the womb to their Biobag device. While an advance, the potential for vascular spasm was not entirely ameliorated. In one study, $30 \%$ of animals died due to vascular spasm limiting flows (62).

A collaborative Western Australian-based program involving researchers from the Women and Infants Research Foundation, the University of Western Australia, and Tohoku University Hospital in Japan have developed a similar pumpless AV-ECLS AP platform called the ex vivo intrauterine environment (EVE) system. This system began development with the goal of addressing two problems that hampered previous attempts at a pumpless AP. First, they decreased the volume and resistance of the circuit by including a smaller, lower-resistance oxygenator. Second, they administered vasodilators to the fetus to maintain adequate organ circulation. With this system, they were able to support 5 premature lambs for $18.2 \pm 3.2$ hours (64). Placing a second oxygenator in parallel reduced circuit resistance and prolonged survival to 60 hours (65). The EVE system includes a "biobag" filled with artificial amniotic fluid, which had early issues with bacteremia (66). They have subsequently achieved support up to 1 week in 5 of 6 preterm lambs without bacteremia (67).

Pumpless support using AV-ECLS (EXTEND and EVE platforms) requires 8-12 Fr cannulas and the absence of umbilical vessel spasm to maintain adequate flows. Therefore, this approach is predicated on immediate transfer of the fetus from the womb to an "artificial womb." The different vascular-access and perfusion strategies for the AP determine the diverse approaches to clinical application that will be addressed later.

\section{Pump-driven VV-ECLS}

We hypothesized that veno-venous (VV) ECLS with right atrial drainage and umbilical vein reinfusion would surmount the challenges of an AV approach while still maintaining fetal circulation and adequate gas exchange. Using VV-ECLS with a pump, right atrial drainage, and umbilical vein reinfusion places the circuit in parallel with the systemic circulation, thereby adding little to no increased afterload on the patient's heart (68). With the goal of clinical translation for a premature infant after delivery, we posited this cannulation strategy would allow for an adequately sized drainage cannula in the right atrium via the internal jugular vein and a smaller but acceptably sized umbilical vein cannula without limiting flows. This vascular access strategy has been used previously with traditional ECLS. White and colleagues supported three premature infants with VV-ECLS using the umbilical vein for reinfusion. These babies lived for 10, 3, and 2 days with good gas-exchange parameters, but all died of bleeding complications (69). Subsequently, this approach has been used clinically in 4 term or near-term neonates with good outcomes (70).

We developed a model for an AP based on pump-driven VV-ECLS in 2012 (71). We supported 5 premature lambs (EGA 130-135 days; term =145) using jugular vein drainage and umbilical vein reinfusion for over 24 hours with stable hemodynamics and appropriate fetal gas exchange. Mean AP flow was $94 \pm 20 \mathrm{~mL} / \mathrm{kg} / \mathrm{min}$. Necropsy revealed a patent ductus arteriosus, foramen ovale, and sinus venosus. There was no difference in lung histology between the AP animals and controls and there was no gross or microscopic ICH.

After establishing feasibility of VV-ECLS support, we sought to extend the duration of AP support and determine if premature lambs could be rescued by the AP and fetal circulation re-initiated, thus recreating a likely clinical scenario. To test this hypothesis, 7 premature sheep were delivered, intubated, and started on pressure-control ventilation. All sheep failed (persistent $\mathrm{pO}_{2}<60 \mathrm{mmHg}$ and/ or $\mathrm{pCO}_{2}>100 \mathrm{mmHg}$ or hemodynamic instability) within 80 minutes and were transitioned to VV-ECLS AP support. Within an hour, arterial $\mathrm{pO}_{2}$ and $\mathrm{pCO}_{2}$ returned to target range; lactate normalized within 13 hours. Necropsy after 70 hours of support revealed a patent ductus arteriosus, foramen ovale, and sinus venosus in all sheep (72). This study demonstrated that the AP can serve as a rescue therapy after failure of mechanical ventilation.

We then compared the AP to the current standard of care with mechanical ventilation including HFOV (73). Extremely premature lambs were supported for 1 week with the AP. Despite surfactant and HFOV, the mechanically ventilated animals only survived $2-8$ hours. Recent experience in our lab demonstrates 2-3 weeks of AP support before weaning to mechanical ventilation.

\section{Airway management}

Although all AP systems maintain fluid-filled lungs and avoid gas ventilation, there are two distinct approaches based 
in part on the vascular access strategy. The pumpless AVECLS EXTEND and EVE systems both use a fluid-filled Biobag as an "artificial womb". This is a closed environment with continuous fluid exchange. They have made substantial advances in reducing the infections that had previously plagued this approach $(63,67,74)$. This approach is necessary, in part, to prevent the umbilical vasospasm in a transumbilical AV-ECLS system. Proponents of this approach point out that it recreates the intrauterine environment and allows for normal glottic resistance required for maintenance of normal airway pressures and lung growth.

An alternative approach is to recreate critical fetal physiology, not necessarily replicate the entire womb. Our lab has developed an approach to lung management that is simpler, is equally effective, and has demonstrated ongoing lung maturation. After delivery, we intubate the fetal lamb and fill its lungs with liquid perfluorocarbon-an inert liquid that is not absorbed by the lungs and thus will not cause tissue edema or fluid and electrolyte shifts—-to a level of $5-8 \mathrm{cmH}_{2} \mathrm{O}$ which allows for fetal breathing movements. We then maintain the baby in a standard incubator. This approach resulted in lung development similar to gestational-age-matched controls and reduced lung injury compared to alternative management strategies (75). This has become our standard airway-management strategy and has continued to provide evidence of lung development in later studies $(76,77)$. This strategy could be modified to accelerate lung growth (78), and transition from the AP to liquid ventilation before air breathing (79).

An artificial womb makes the AP system notably more complicated and may limit its clinical translation. It may hinder the provision of clinical care for the baby by the neonatal ICU team, limit the family's ability to physically bond with the baby, potentially increase the risk of infection, and complicate resuscitation if AP support fails. Such a system would require a significant amount of new, specialized equipment and training that may not be available at many centers.

\section{Organ development}

A central tenet of the AP is to recreate fetal physiology to allow for organ protection and continued development. We have closely examined lung development from both a functional and histopathological standpoint using VVECLS and fluid-filled lungs. Church et al. cannulated 5 extremely premature lambs (EGA 118 days) for 10 days of AP support (76). At the end of the AP run, lambs were transitioned to mechanical ventilation and lung function was evaluated. These were compared to 5 early ventilator controls (EGA 118 days) and 5 late ventilator controls (EGA 128 days). Lung compliance and oxygenation index at the conclusion of the AP run were similar to late ventilator controls. On histologic examination, lungs of the AP animals demonstrated a significantly higher level of active development than both early and late ventilator controls, as measured by area fractions of alveolar tips double-positive for both $\alpha$-actin and PDGFR- $\alpha$. A second study designed to evaluate lung development and injury placed premature sheep on the AP at 114-121 days EGA for 7 days of support (77). They were compared to EGA-matched ventilator controls as well as EGA-matched tissue controls. This study demonstrated that the AP is protective against lung injury and promotes lung development compared with mechanical ventilation in premature lambs (Figure 1).

Similarly, there was evidence of lung maturation during support with EXTEND. Using morphometric analysis, histologic assessment, and surfactant protein $\mathrm{B}$ analysis, they demonstrated progression from the canalicular to saccular stages of lung development. Physiologically, pulmonary function of lambs weaned from EXTEND was similar to age-matched controls (74).

Two studies have demonstrated that the brains of premature sheep supported by an AP using VV-ECLS are well perfused and develop normally with minimal evidence of injury. El-Sabbagh cannulated 14 premature lambs (EGA 130 days) for the AP with jugular vein drainage and umbilical vein reinfusion (80). Lambs were supported on the AP for $55 \pm 27$ hours. The percentage of cerebral regional oxygen saturation (as measured by near-infrared spectroscopy monitor on the scalp) for lambs on AP support was $50 \% \pm 11 \%$ compared to $40 \% \pm 3 \%$ at baseline on native placental support. Carotid artery flow during AP support was unchanged from baseline. Cerebral fractional tissue oxygen extraction-calculated as the relative difference between arterial saturation and cerebral regional saturation-was unchanged from baseline during AP support, suggesting a balance between cerebral oxygen consumption and oxygen delivery. A subsequent study compared the brain development and injury of 4 lambs (EGA 118 days) supported on the AP for 7 days with 4 early ventilator controls (EGA 118 days), 4 late ventilator controls (EGA 127 days), 5 early tissue controls (EGA $118 \pm 3$ days) and 5 late tissue controls (EGA $128 \pm 3$ days) (81). The ventilator controls were supported on a conventional ventilator for 

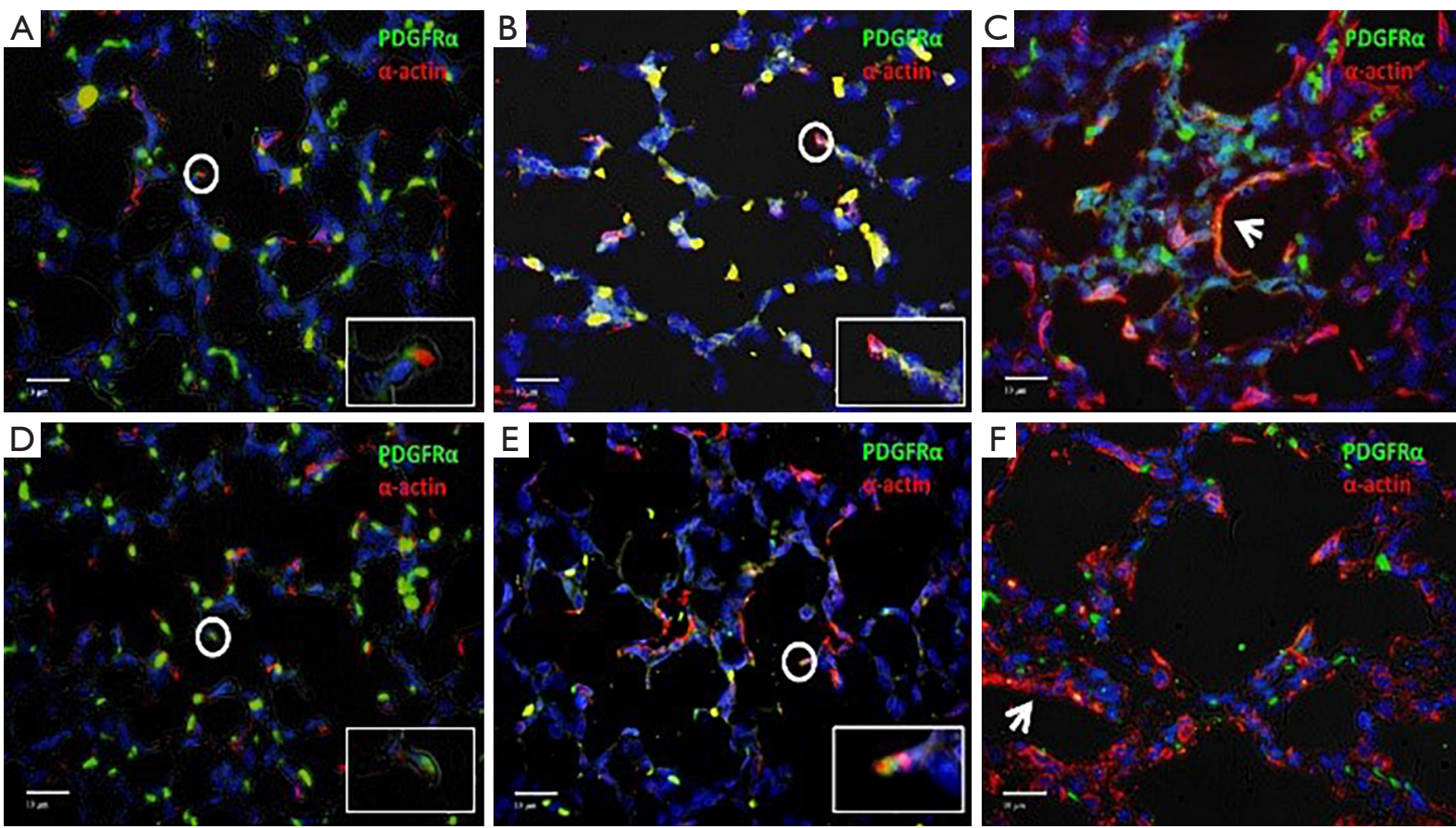

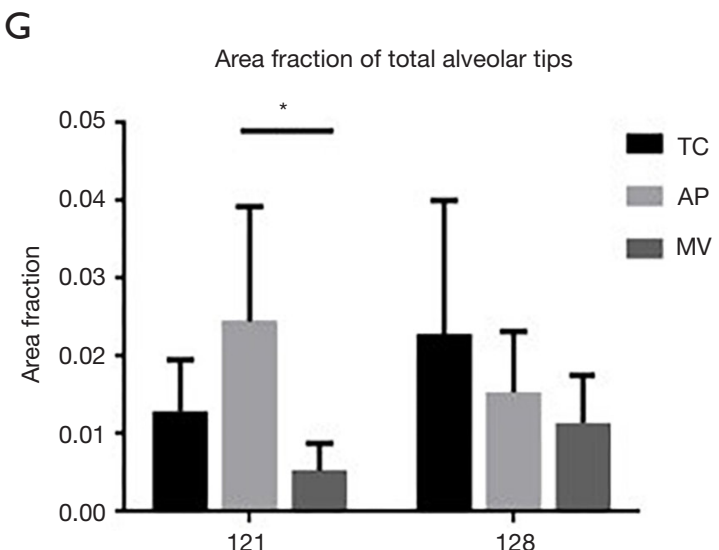

Estimated gestational age (days)
$\mathrm{H}$



Estimated gestational age (days)

Figure 1 Immunostaining for markers of lung development. Representative slides of lungs at 40x magnification, immunostained for $\alpha$-smooth muscle actin (red) and platelet-derived growth factor- $\alpha$ (green). (A) Early TC, (B) Early AP, (C) Early MV, (D) Late TC, (E) Late AP, (F) Late MV. Circles highlight alveolar tips with adjacent $\alpha$-actin and PDGFR $\alpha$ staining or colocalization of $\alpha$-smooth muscle actin and PDGFR (orange or yellow), which are enlarged for detail in inset images. Arrows indicate interstitial $\alpha$-smooth muscle actin (G) total tip area fractions identified by histologic appearance, and $(\mathrm{H})$ positive tip area fractions, defined as the ratio of reference points falling on total or double-positive alveolar tips, respectively, divided by the total number of reference points. Area fractions were determined for 5 slides from each sample and then averaged to produce an area fraction for that sample. $\mathrm{N}=5$ for all groups, except $\mathrm{n}=3$ for Early AP. Mean $\pm \mathrm{SD}$, *, $\mathrm{P}<0.05$, ANOVA. Figure with permission from Church 2018 (76). 




Figure 2 MRI analysis of brain development on the AP. The brains of premature lambs show continued normal development and myelination of frontal white matter as measured by fractional anisotropy, shown here in a representative axial slice of a postmortem brain MRI of a lamb supported by the AP for 7 days. Yellow arrows identify frontal white matter.

up to 48 hours prior to euthanasia. The brains of each sheep were prepared and put through an MRI scan. No intracerebral hemorrhage was seen in any lambs supported on the AP. There was no evidence of white-matter injurymeasured by fractional anisotropy and apparent diffusion coefficient in multiple structures-in the AP group, while the early ventilator control group did demonstrate evidence of injury compared to the age-matched tissue control group. The AP group manifested ongoing development of the frontal white matter, as evidenced by similar fractional anisotropy to that of the late tissue controls (Figure 2).

Brain protection and ongoing development has also been assessed with AV-ECLS systems. McGovern et al. studied 18 lambs on EXTEND and either analyzed by neuropathology, functional assessment, or MRI. They found no evidence of neurologic injury or white matter injury. The degree of myelination was consistent with age-matched controls. Animals that transitioned from the system have no persistent neurologic deficits (82). In the EVE system, there was evidence of white matter injury in 2/5 lambs who were supported for 1 week (67). In a subsequent study of extremely premature lambs (95 days EGA) they found no evidence of hemorrhage and only one of seven lambs had white matter injury (83).

The bowel and the spleen also continue to develop on the AP with little to no injury. To evaluate the bowel, 5 premature lambs (EGA 116-121 days) were supported on the AP for 7 days (84). They received TPN during the entire run. The AP group had a greater degree of enterocyte proliferation than the early and late tissue controls, but similar mucosal architecture. Some animals in the AP group did have evidence of mild injury, though this was not significantly different from the controls (84). The effects of the AP on the spleen were evaluated in 14 premature lambs supported by the AP for $12 \pm 5$ days (85). Splenic development was similar in the AP group and early and late tissue control groups. Extramedullary hematopoiesis appeared to transition away from the spleen in the AP group. The spleens in the AP group demonstrated an expected macrophage-mediated inflammatory response (85). Preliminary data on the liver, kidney, and heart also suggest organ protection and ongoing development.

The EXTEND system is particularly well-suited to studying abnormal fetal development. It has proven to be a superb platform for studying the effects of chronic intrauterine hypoxia on mitochondria (86), myocardial development (87), and neurodevelopment (88-90).

\section{Future challenges and innovation}

\section{Cannulation and perfusion strategy}

Current versions of the AP use some form of umbilical access. Cannulation of these vessels is straightforward in animal models in which access can be secured in a controlled fashion while the animal is still connected to the mother's placenta, prior to the onset of vasospasm or desiccation of the cord. Translation of this technique to clinical use would require an Ex Utero Intrapartum Treatment (EXIT) procedure or modified cesarean delivery with the AV-ECLS approach. Alternatively, cannulation can be performed after delivery but spasm of the umbilical vessels could limit cannula size with the VV-ECLS approach.

To address this challenge, surgeons must develop techniques for limiting post-delivery vasospasm of the umbilical vessels or identify an alternative cannulation strategy. Peng et al. performed ex vivo dilation of segments of umbilical vessels immediately after delivery to determine the extent to which these vessels could be dilated postdelivery to facilitate cannulation. They found a dilation threshold of $7 \mathrm{~mm}$ for the umbilical vein and $6 \mathrm{~mm}$ for the umbilical artery (91), suggesting that large-bore cannulation of these vessels may be feasible. 


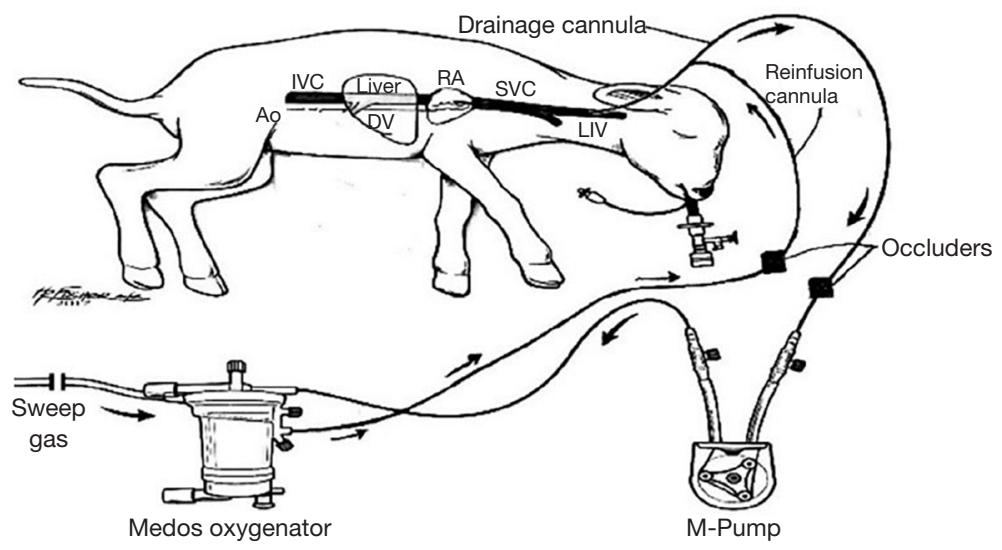

Figure 3 Tidal-flow circuit configuration. Cannulation is with a single-lumen cannula placed in the jugular vein. Both the reinfusion and drainage line connect to this cannula with a modified Y-connector. Occluders are placed on each line, intermittently occluding the drainage and reinfusion lines in an alternating fashion. The M-Pump is a non-occlusive roller pump that serves as a distensible reservoir to accommodate the fluctuations in circuit volume that occur with each cycle of the occluders. Figure with permission from Kading 2019 (93).

Another approach is the use of a single cannula in the internal jugular vein, obviating the need for umbilical access altogether. This cannulation strategy is commonly used in ECMO through a dual-lumen cannula; however, a dual-lumen cannula would not provide adequate flows when miniaturized to 5-6 Fr. An alternative single-vessel, trans-jugular approach was developed over 30 years ago at the University of Michigan (92). This system uses tidalflow perfusion through a single-lumen cannula (Figure 3). It is currently being evaluated as a potential perfusion strategy for the AP. A major benefit of this system is that it allows for maximization of the diameter of the drainage cannula-the limiting variable in extracorporeal support. The primary limitation of this system is recirculationoccurring with each transition between drainage and reinfusion-which decreases the efficiency of the oxygen delivery. Longer occluder cycle times reduce the degree of recirculation but are also associated with larger volume and pressure fluctuations for the patient, which can result in hemodynamic instability and hemolysis. In our most recent work with the tidal-flow system, we have supported 3 premature sheep (EGA 118-124 days) for 24 hours, maintaining adequate gas exchange and hemodynamics (93). Further studies in our lab have achieved up to 7 days of support (unpublished data).

\section{Miniaturization}

Premature infants born at 23-27 weeks typically weigh
500-800 g. Most premature sheep models used for artificial placenta development use 110-120 days EGA sheep because they are equivalent to the lung development of 23-24 weeks human infants. However, they weigh $2-4 \mathrm{~kg}$, which greatly exceeds the weight of the target patient population. For the VV-ECLS approach, the smaller sized animals may require alterations in vascular access techniques and perfusion as described above. Adequacy of support will need to be demonstrated with changes in clinical condition and somatic growth.

Technical and physiologic feasibility of miniaturizing the pumpless AV-ECLS approach has been reported. In the animal models, $8-12 \mathrm{~F}$ cannulas were placed during an EXIT procedure obviating size limitations from umbilical vessel spasm. Using EXTEND, 5 extremely preterm (EGA 85-96 days) lambs weighing 480-850 g were cannulated via the umbilical artery and umbilical vein and supported for 4-7 days with mean circuit flows of $213 \mathrm{~mL} / \mathrm{kg} / \mathrm{min}$ and stable gas exchange and hemodynamics (94). However, all lambs developed hydrops leading to demise. The researchers speculate this was due to cardiac immaturity and inability to accommodate high post-membrane pressures. In a similar miniaturization study using the EVE platform, seven out of eight lambs (EGA 95 days) survived for 5 days on support with good gas exchange, stable hemodynamics and normal echocardiographic parameters. Interestingly, despite circuit flows well above $200 \mathrm{~mL} / \mathrm{kg} / \mathrm{min}$ in all animals, there was no evidence of high output cardiac failure or hydrops (83). While these preliminary findings 
are promising, the ability of extremely premature infants to tolerate these hemodynamic changes remains unknown.

\section{Nonthrombogenic circuits and fetal bemoglobin}

The risk of systemic anticoagulation in ELGANs is prohibitively high to allow it to be an acceptable strategy for use in the AP. Our lab has developed a nitric oxide surfacebased anticoagulation (NOSA) system to obviate the need for systemic anticoagulation. The surface coating is based on S-nitroso-N-acetylpenicillamine (SNAP) $(95,96)$. NO is secreted by the normal endothelium at a flux rate of $(0.5-4.0) \times 10^{-10} \mathrm{~mol} / \mathrm{cm}^{2} / \mathrm{min}$ and prevents platelet adhesion and activation without affecting platelet function $(97,98)$. $\mathrm{NO}$ is released from SNAP-based polymer coatings in flux units of $0.5-4$ for as long as 20 days and has been shown to prevent thrombosis $(96,98,99)$. We found that adding the direct thrombin inhibitor argatroban to the coating reduces fibrin formation $(100,101)$. Since the oxygenator cannot be coated as this would interfere with gas exchange, we have developed a method to deliver $85 \mathrm{ppm}$ of $\mathrm{NO}$ into the sweep gas using electrochemical generation from nitrite solution containing copper complexes that mimic the active site of nitrite reductase enzymes $(102,103)$. Preliminary data in the AP model is very promising and would be a breakthrough for clinical translation.

Clinical application of the AP will require priming of the circuit and blood transfusions, although this may be mitigated in part by using high doses of erythropoietin (104). Currently, banked blood is from adult donors and devoid of fetal hemoglobin ( $\mathrm{HbF}$ ) which is optimal for oxygen transfer in a low-oxygen fetal environment. As $\mathrm{HbF}$ declines with transfusions of adult blood, the $\mathrm{pO}_{2}$ will need to be increased to meet metabolic demands. This could have deleterious effects on fetal circulation and may potentiate spasm of umbilical vessels in the AV-ECLS approach. Further study will be required before long-term application of the AP.

\section{Clinical translation}

Although the pumpless AV-ECLS platforms more closely recreate intrauterine physiology, clinical application would require an EXIT procedure or a modified cesarean section with a classical incision. The incidence of maternal intraoperative adverse events associated with cesarean deliveries at 24-25 weeks was $63.5 \%$ compared to $30.8 \%$ at 26-27 weeks (105); an emergent EXIT procedure would further increase these risks. Furthermore, a classical caesarian section would be required as the lower uterine segment is not developed early in gestation. The higher rates of classical incisions raise concerns about risks of uterine rupture, placental insertion abnormalities, and repeat cesareans in future pregnancies. Lannon et al. confirmed this in their study, which reported a risk of uterine rupture nearly five times higher among women whose previous cesarean took place before 26 weeks compared with at term (106). As it relates to the fetus, this approach would lack any risk stratification for the infant apart from gestational age. Further work is required to mitigate these potential maternal risks and refine patient selection.

The approach to patient selection for a postnatal VVECLS AP is two-fold. Similar to inclusion criteria for ECMO, it could be applied to critically ill premature infants after failing maximal medical therapy. This cohort would be expected to have suffered significant barotrauma and may not reap all the lung protective and developmental benefits of an artificial placenta. It could also be applied before respiratory failure in a cohort of ELGANs anticipated to have high mortality and morbidity according to riskstratification metrics. The Score of Neonatal Acute Physiology Perinatal Extension (SNAPPE-II) and the Clinical Risk Index for Babies II (CRIB II) have been developed to estimate mortality risk in premature neonates. Recent studies suggest these markers may be useful in predicting high mortality in premature infants in the early newborn period $(107,108)$. The National Institutes of Health Eunice Kennedy Shriver National Institute of Child Health and Human Development has developed the Extremely Preterm Birth Outcomes Tool to provide a range of possible outcomes for infants born extremely prematurely with particular characteristics, though it does caution against its use as a predictive tool for any individual patient (109). These will serve as good starting points but will need to be validated for their use as predictive models to identify the best candidates for AP support.

Since all extracorporeal support is fraught with potential complications, clinical application should be judicious. In order to have the greatest impact on morbidity and mortality of premature infants, the AP should be widely available and easily implemented at any neonatal ECMO center. When patient selection criteria are refined, there may be a hybrid approach to clinical application based on careful consideration of risks and benefits. Fetuses at the border of viability may benefit from a preemptive AV-ECLS 
approach while fetuses precipitously delivered or older ELGANs may benefit from a postnatal VV-ECLS approach after risk stratification.

\section{Conclusions}

In the past decade, advances in developing an AP for support of extremely premature infants have accelerated and coalesced. Two related but distinct platforms have emerged (pumpless AV-ECLS and pump-driven VV-ECLS). These have been modified to mimic fetal physiology and allow prolonged support and ongoing organ development. After surmounting the remaining technical and clinical barriers, clinical translation of the $\mathrm{AP}$ in the near future is promising.

\section{Acknowledgments}

Funding: None.

\section{Footnote}

Provenance and Peer Review: This article was commissioned by the Guest Editors (Eric B. Jelin and George B. Mychaliska) for the series "Fetal Surgery" published in Translational Pediatrics. The article was sent for external peer review organized by the Guest Editors and the editorial office.

Reporting Checklist: The authors have completed the narrative review reporting checklist. Available at http:// dx.doi.org/10.21037/tp-20-136

Conflicts of Interest: Both authors have completed the ICMJE uniform disclosure form (available at http://dx.doi. org/10.21037/tp-20-136). The series "Fetal Surgery" was commissioned by the editorial office without any funding or sponsorship. Dr. GBM served as the unpaid Guest Editor of the series. The authors have no other conflicts of interest to declare.

Ethical Statement: The authors are accountable for all aspects of the work in ensuring that questions related to the accuracy or integrity of any part of the work are appropriately investigated and resolved.

Open Access Statement: This is an Open Access article distributed in accordance with the Creative Commons Attribution-NonCommercial-NoDerivs 4.0 International
License (CC BY-NC-ND 4.0), which permits the noncommercial replication and distribution of the article with the strict proviso that no changes or edits are made and the original work is properly cited (including links to both the formal publication through the relevant DOI and the license). See: https://creativecommons.org/licenses/by-nc-nd/4.0/.

\section{References}

1. Ely DM, Driscoll AK. Infant mortality in the United States, 2017: data from the period linked birth/infant death file 2019.

2. Norman M, Hallberg B, Abrahamsson T, et al. Association Between Year of Birth and 1-Year Survival Among Extremely Preterm Infants in Sweden During 2004-2007 and 2014-2016. JAMA 2019;321:1188.

3. Patel RM, Kandefer S, Walsh MC, et al. Causes and timing of death in extremely premature infants from 2000 through 2011. N Engl J Med 2015;372:331-40.

4. Ishii N, Kono Y, Yonemoto N, et al. Outcomes of infants born at 22 and 23 weeks' gestation. Pediatrics 2013;132:62-71.

5. Stoll BJ, Hansen NI, Bell EF, et al. Neonatal outcomes of extremely preterm infants from the NICHD Neonatal Research Network. Pediatrics 2010;126:443-56.

6. Crump C, Winkleby MA, Sundquist J, et al. Prevalence of survival without major comorbidities among adults born prematurely. JAMA 2019;322:1580-8.

7. Dreyfuss D, Saumon G. Ventilator-induced lung injury: lessons from experimental studies. Am J Respir Crit Care Med 1998;157:294-323.

8. Lang JA, Pearson JT, Binder-Heschl C, et al. Increase in pulmonary blood flow at birth: role of oxygen and lung aeration. J Physiol 2016;594:1389-98.

9. Biondi JW, Schulman DS, Soufer R, et al. The effect of incremental positive end-expiratory pressure on right ventricular hemodynamics and ejection fraction. Anesth Analg 1988;67:144-51.

10. Aly H, Hammad TA, Essers J, et al. Is mechanical ventilation associated with intraventricular hemorrhage in preterm infants? Brain Dev 2012;34:201-5.

11. Cayabyab R, Ramanathan R. Retinopathy of Prematurity: Therapeutic Strategies Based on Pathophysiology. Neonatology 2016;109:369-76.

12. Fischer HS, Buhrer C. Avoiding endotracheal ventilation to prevent bronchopulmonary dysplasia: a meta-analysis. Pediatrics 2013;132:e1351-60.

13. Schmölzer GM, Kumar M, Pichler G, et al. Non- 
invasive versus invasive respiratory support in preterm infants at birth: systematic review and meta-analysis. BMJ 2013;347:f5980.

14. Subramaniam P, Ho JJ, Davis PG. Prophylactic nasal continuous positive airway pressure for preventing morbidity and mortality in very preterm infants. Cochrane Database Syst Rev 2016;(6):CD001243.

15. Lemyre B, Laughon M, Bose C, et al. Early nasal intermittent positive pressure ventilation (NIPPV) versus early nasal continuous positive airway pressure (NCPAP) for preterm infants. Cochrane Database Syst Rev 2016;12:CD005384.

16. Supplemental Therapeutic Oxygen for Prethreshold Retinopathy Of Prematurity (STOP-ROP), a randomized, controlled trial. I: primary outcomes. Pediatrics 2000;105:295-310.

17. Carlo WA, Stark AR, Wright LL, et al. Minimal ventilation to prevent bronchopulmonary dysplasia in extremely-lowbirth-weight infants. J Pediatr 2002;141:370-4.

18. Mariani G, Cifuentes J, Carlo WA. Randomized trial of permissive hypercapnia in preterm infants. Pediatrics 1999;104:1082-8.

19. Woodgate PG, Davies MW. Permissive hypercapnia for the prevention of morbidity and mortality in mechanically ventilated newborn infants. Cochrane Database Syst Rev 2001;(2):CD002061.

20. Robbins M, Trittmann J, Martin E, et al. Early extubation attempts reduce length of stay in extremely preterm infants even if re-intubation is necessary. J Neonatal Perinatal Med 2015;8:91-7.

21. Al Faleh K, Liew K, Anabrees J, et al. Success rate and neonatal morbidities associated with early extubation in extremely low birth weight infants. Ann Saudi Med 2011;31:577-80.

22. Askie LM, Darlow BA, Davis PG, et al. Effects of targeting lower versus higher arterial oxygen saturations on death or disability in preterm infants. Cochrane Database Syst Rev 2017;4:CD011190.

23. Manja V, Lakshminrusimha S, Cook DJ. Oxygen saturation target range for extremely preterm infants: a systematic review and meta-analysis. JAMA Pediatr 2015;169:332-40.

24. Manja V, Saugstad OD, Lakshminrusimha S. Oxygen saturation targets in preterm infants and outcomes at 18-24 months: a systematic review. Pediatrics 2017;139:e20161609.

25. Askie LM, Darlow BA, Finer N, et al. Association between oxygen saturation targeting and death or disability in extremely preterm infants in the neonatal oxygenation prospective meta-analysis collaboration. JAMA 2018;319:2190-201.

26. Wheeler KI, Klingenberg C, Morley CJ, et al. Volumetargeted versus pressure-limited ventilation for preterm infants: a systematic review and meta-analysis. Neonatology 2011;100:219-27.

27. Beck J, Reilly M, Grasselli G, et al. Patient-Ventilator interaction during neurally adjusted ventilatory assist in low birth weight infants. Pediatric Research 2009;65:663-8.

28. Lee J, Kim HS, Sohn JA, et al. Randomized crossover study of neurally adjusted ventilatory assist in preterm infants. J Pediatr 2012;161:808-13.

29. Cools F, Askie LM, Offringa M, et al. Elective highfrequency oscillatory versus conventional ventilation in preterm infants: a systematic review and meta-analysis of individual patients' data. Lancet 2010;375:2082-91.

30. Cools F, Offringa M, Askie LM. Elective high frequency oscillatory ventilation versus conventional ventilation for acute pulmonary dysfunction in preterm infants. Cochrane Database Syst Rev 2015;(3):CD000104.

31. Liggins GC, Howie RN. A controlled trial of antepartum glucocorticoid treatment for prevention of the respiratory distress syndrome in premature infants. Pediatrics 1972;50:515-25.

32. Roberts D, Brown J, Medley N, et al. Antenatal corticosteroids for accelerating fetal lung maturation for women at risk of preterm birth. Cochrane Database Syst Rev 2017;3:CD004454.

33. Rojas-Reyes MX, Morley CJ, Soll R. Prophylactic versus selective use of surfactant in preventing morbidity and mortality in preterm infants. Cochrane Database Syst Rev 2012;(3):CD000510.

34. Venkataraman R, Kamaluddeen M, Hasan SU, et al. Intratracheal administration of budesonide-surfactant in prevention of bronchopulmonary dysplasia in very low birth weight infants: a systematic review and meta-analysis. Pediatr Pulmonol 2017;52:968-75.

35. Gibbon JH Jr. Application of a mechanical heart and lung apparatus to cardiac surgery. Minn Med 1954;37:171-85; passim.

36. Westin B, Nyberg R, Enhörning G. A technique for perfusion of the previable human fetus. Acta Paediatr 1958;47:339-49.

37. Lawn L, McCance RA. Ventures with an artificial placenta - I. Principles and preliminary results. Proceedings of the Royal Society of London Series B Biological Sciences 1962;155:500-9.

38. Lawn L MR. Ventures with an artificial placenta I. 
Principles and preliminary results. Proc Roy Soc 1962;155:500-9.

39. Lawn L, Mccance RA. Artificial placentae: A progress report. Acta Paediatr 1964;53:317-25.

40. Alexander DP, Britton HG, Nixon DA. Maintenance of sheep fetuses by an extracorporeal circuit for periods up to 24 hours. Am J Obstet Gynecol 1968;102:969-75.

41. Callaghan JC, Angeles J, Boracchia B, et al. Studies of the first successful delivery of an unborn lamb after 40 minutes in the artificial placenta. Can J Surg 1963;6:199-206.

42. Callaghan JC, Boracchia B, Fisk RL, et al. Studies in the development of an artificial placenta the possible use of long-term extracorporeal circulation for respiratory distress of the newborn. Circulation 1963;27:686-90.

43. Callaghan JC, Angeles JD. Long-term extracorporeal circulation in the development of an artificial placenta for respiratory distress of the newborn. Surg Forum 1961;12:215-7.

44. Zapol WM, Kolobow T, Pierce JE, et al. Artificial Placenta: Two Days of Total Extrauterine Support of the Isolated Premature Lamb Fetus. Science 1969;166:617-8.

45. Ballard PL, Granberg P, Ballard RA. Glucocorticoid levels in maternal and cord serum after prenatal betamethasone therapy to prevent respiratory distress syndrome. J Clin Invest 1975;56:1548-54.

46. Kattner E, Metze B, Waiß E, et al. Accelerated lung maturation following maternal steroid treatment in infants born before 30 weeks gestation. J Perinat Med 1992;20:449-57.

47. Bohn DJ, Miyasaka K, Marchak BE, et al. Ventilation by high-frequency oscillation. J Appl Physiol 1980;48:710-6.

48. Bartlett RH, Gazzaniga AB, Jefferies MR, et al. Extracorporeal membrane oxygenation (ECMO) cardiopulmonary support in infancy. Trans Am Soc Artif Intern Organs 1976;22:80-93.

49. Bartlett RH. Extracorporeal life support: history and new directions. Semin Perinatol 2005;29:2-7.

50. Bartlett RH, Andrews AF, Toomasian JM, et al. Extracorporeal membrane oxygenation for newborn respiratory failure: forty-five cases. Surgery 1982;92:425-33.

51. Mahmood B, Newton D, Pallotto EK. Current trends in neonatal ECMO. Semin Perinatol 2018;42:80-8.

52. Church JT, Kim AC, Erickson KM, et al. Pushing the boundaries of ECLS: Outcomes in <34 week EGA neonates. J Pediatr Surg 2017;52:1810-5.

53. Griffith BP, Borovetz HS, Hardesty RL, et al. Arteriovenous ECMO for neonatal respiratory support: a study in perigestational lambs. J Thorac Cardiovasc Surg
1979;77:595-601.

54. Kuwabara Y, Okai T, Imanishi Y, et al. Development of extrauterine fetal incubation system using extracorporeal membrane oxygenator. Artif Organs 1987;11:224-7.

55. Kuwabara Y, Okai T, Kozuma S, et al. Artificial Placenta: Long-Term Extrauterine Incubation of Isolated Goat Fetuses. Artif Organs 1989;13:527-31.

56. Unno N, Kuwabara Y, Shinozuka N, et al. Development of Artificial Placenta: Oxygen Metabolism of Isolated Goat Fetuses with Umbilical Arteriovenous Extracorporeal Membrane Oxygenation. Fetal Diagn Ther 1990;5:189-95.

57. Unno N, Kuwabara Y, Okai T, et al. Development of an Artificial Placenta: Survival of Isolated Goat Fetuses for Three Weeks with Umbilical Arteriovenous Extracorporeal Membrane Oxygenation. Artif Organs 1993;17:996-1003.

58. Sakata M, Hisano K, Okada $M$, et al. A new artificial placenta with a centrifugal pump: long-term total extrauterine support of goat fetuses. J Thorac Cardiovasc Surg 1998;115:1023-31.

59. Ivascu FA, Somand DM, Skrzypchak AM, et al. Development of an artificial placenta: $\mathrm{CO} 2$ elimination and hemodynamics as a function of arteriovenous blood flow. J Pediatr Surg 2005;40:1034-7.

60. Reoma JL, Rojas A, Kim AC, et al. Development of an artificial placenta I: pumpless arterio-venous extracorporeal life support in a neonatal sheep model. J Pediatr Surg 2009;44:53-9.

61. Hornick MA, Davey MG, Partridge EA, et al. Umbilical cannulation optimizes circuit flows in premature lambs supported by the EXTra-uterine Environment for Neonatal Development (EXTEND). J Physiol 2018;596:1575-85.

62. Ozawa K, Davey MG, Tian Z, et al. Fetal echocardiographic assessment of cardiovascular impact of prolonged support on EXTrauterine Environment for Neonatal Development (EXTEND) system. Ultrasound Obstet Gynecol 2020;55:516-22.

63. Partridge EA, Davey MG, Hornick MA, et al. An EXTrauterine environment for neonatal development: EXTENDING fetal physiology beyond the womb. Semin Fetal Neonatal Med 2017;22:404-9.

64. Miura Y, Matsuda T, Funakubo A, et al. Novel modification of an artificial placenta: pumpless arteriovenous extracorporeal life support in a premature lamb model. Pediatr Res 2012;72:490-4.

65. Miura Y, Matsuda T, Usuda H, et al. A Parallelized Pumpless Artificial Placenta System Significantly Prolonged Survival Time in a Preterm Lamb Model. Artif 
Organs 2016;40:E61-8.

66. Miura Y, Usuda H, Watanabe S, et al. Stable control of physiological parameters, but not infection, in preterm lambs maintained on ex vivo uterine environment therapy. Artif Organs 2017;41:959-68.

67. Usuda H, Watanabe S, Miura Y, et al. Successful maintenance of key physiological parameters in preterm lambs treated with ex vivo uterine environment therapy for a period of 1 week. Am J Obstet Gynecol 2017;217:457.e1-e13.

68. Skinner SC, Hirschl RB, Bartlett RH. Extracorporeal life support. Semin Pediatr Surg 2006;15:242-50.

69. White JJ, Andrews HG, Risemberg H, et al. Prolonged respiratory support in newborn infants with a membrane oxygenator. Surgery 1971;70:288-96.

70. Kato J, Nagaya M, Niimi N, et al. Venovenous extracorporeal membrane oxygenation in newborn infants using the umbilical vein as a reinfusion route. J Pediatr Surg 1998;33:1446-8.

71. Gray BW, El-Sabbagh A, Rojas-Pena A, et al. Development of an artificial placenta IV: 24 hour venovenous extracorporeal life support in premature lambs. ASAIO J 2012;58:148-54.

72. Gray BW, El-Sabbagh A, Zakem SJ, et al. Development of an artificial placenta V: $70 \mathrm{~h}$ veno-venous extracorporeal life support after ventilatory failure in premature lambs. J Pediatr Surg 2013;48:145-53.

73. Bryner B, Gray B, Perkins E, et al. An extracorporeal artificial placenta supports extremely premature lambs for 1 week. J Pediatr Surg 2015;50:44-9.

74. Partridge EA, Davey MG, Hornick MA, et al. An extrauterine system to physiologically support the extreme premature lamb. Nat Commun 2017;8:15112.

75. Church JT, Perkins EM, Coughlin MA, et al. Perfluorocarbons prevent lung injury and promote development during artificial placenta support in extremely premature lambs. Neonatology 2018;113:313-21.

76. Church JT, Coughlin MA, Perkins EM, et al. The artificial placenta: Continued lung development during extracorporeal support in a preterm lamb model. J Pediatr Surg 2018;53:1896-903.

77. Coughlin MA, Werner NL, Church JT, et al. An Artificial Placenta protects against lung injury and promotes continued lung development in extremely premature lambs. ASAIO J 2019;65:690-7.

78. Mychaliska G, Bryner B, Dechert R, et al. Safety and efficacy of perflubron-induced lung growth in neonates with congenital diaphragmatic hernia: Results of a prospective randomized trial. J Pediatr Surg 2015;50:1083-7.

79. Hirschl RB. Current experience with liquid ventilation. Paediatr Respir Rev 2004;5 Suppl A:S339-45.

80. El-Sabbagh AM, Gray BW, Shaffer AW, et al. Cerebral oxygenation of premature lambs supported by an artificial placenta. ASAIO J 2018;64:552-6.

81. Church JT, Werner NL, Coughlin MA, et al. Effects of an artificial placenta on brain development and injury in premature lambs. J Pediatr Surg 2018;53:1234-9.

82. McGovern PE, Hornick MA, Mejaddam AY, et al. Neurologic outcomes of the premature lamb in an extrauterine environment for neonatal development. J Pediatr Surg 2020;5 5:2115-23.

83. Usuda H, Watanabe S, Saito M, et al. Successful use of an artificial placenta to support extremely preterm ovine fetuses at the border of viability. Am J Obstet Gynecol 2019;221:69.e1-.e17.

84. McLeod JS, Church JT, Yerramilli P, et al. Gastrointestinal mucosal development and injury in premature lambs supported by the artificial placenta. J Pediatr Surg 2018;53:1240-5.

85. McLeod JS, Church JT, Coughlin MA, et al. Splenic development and injury in premature lambs supported by the artificial placenta. J Pediatr Surg 2019;54:1147-52.

86. Rossidis AC, Baumgarten HD, Lawrence KM, et al. Chronically Hypoxic Fetal Lambs Supported by an ExtraUterine Device Exhibit Mitochondrial Dysfunction and Elevations of Hypoxia Inducible Factor 1-Alpha. Fetal Diagn Ther 2019;45:176-83.

87. Lawrence KM, Hennessy-Strahs S, McGovern PE, et al. Fetal hypoxemia causes abnormal myocardial development in a preterm ex utero fetal ovine model. JCI Insight 2018;3:e124338.

88. Lawrence KM, McGovern PE, Mejaddam A, et al. Chronic intrauterine hypoxia alters neurodevelopment in fetal sheep. J Thorac Cardiovasc Surg 2019;157:1982-91.

89. Lawrence KM, McGovern PE, Mejaddam A, et al. Prenatal hypoxemia alters microglial morphology in fetal sheep. J Thorac Cardiovasc Surg 2019. [Epub ahead of print].

90. McGovern PE, Lawrence K, Baumgarten H, et al. Ex Utero Extracorporeal Support as a Model for Fetal Hypoxia and Brain Dysmaturity. Ann Thorac Surg 2020;109:810-9.

91. Peng J, Rochow N, Dabaghi M, et al. Postnatal dilatation of umbilical cord vessels and its impact on wall integrity: Prerequisite for the artificial placenta. Int J Artif Organs 
2018;41:393-9.

92. Zwischenberger JB, Toomasian JM, Drake K, et al. Total respiratory support with single cannula venovenous ECMO: double lumen continuous flow vs. single lumen tidal flow. Trans Am Soc Artif Intern Organs 1985;31:610-5.

93. Kading JC, Langley MW, Lautner G, et al. Tidal Flow Perfusion for the Artificial Placenta: A Paradigm Shift. ASAIO J 2020;66:796-802.

94. Hornick MA, Mejaddam AY, McGovern PE, et al. Technical feasibility of umbilical cannulation in midgestation lambs supported by the EXTra-uterine Environment for Neonatal Development (EXTEND). Artif Organs 2019;43:1154-61.

95. Brisbois EJ, Davis RP, Jones AM, et al. Reduction in Thrombosis and Bacterial Adhesion with 7 Day Implantation of S-Nitroso-N-acetylpenicillamine (SNAP)Doped Elast-eon E2As Catheters in Sheep. J Mater Chem B Mater Biol Med 2015;3:1639-45.

96. Brisbois EJ, Handa H, Major TC, et al. Long-term nitric oxide release and elevated temperature stability with S-nitroso-N-acetylpenicillamine (SNAP)-doped Elast-eon E2As polymer. Biomaterials 2013;34:6957-66.

97. Vaughn MW, Kuo L, Liao JC. Estimation of nitric oxide production and reaction rates in tissue by use of a mathematical model. Am J Physiol 1998;274:H2163-76.

98. Major TC, Brant DO, Reynolds MM, et al. The attenuation of platelet and monocyte activation in a rabbit model of extracorporeal circulation by a nitric oxide releasing polymer. Biomaterials 2010;31:2736-45.

99. Wo Y, Li Z, Brisbois EJ, et al. Origin of Long-Term Storage Stability and Nitric Oxide Release Behavior of CarboSil Polymer Doped with S-Nitroso-N-acetyl-D-penicillamine. ACS Appl Mater Interfaces 2015;7:22218-27.

100.Major TC, Brisbois EJ, Jones AM, et al. The effect of a polyurethane coating incorporating both a thrombin

Cite this article as: Fallon BP, Mychaliska GB. Development of an artificial placenta for support of premature infants: narrative review of the history, recent milestones, and future innovation. Transl Pediatr 2021;10(5):1470-1485. doi: $10.21037 /$ tp-20-136 inhibitor and nitric oxide on hemocompatibility in extracorporeal circulation. Biomaterials 2014;35:7271-85.

101. Yu J, Brisbois E, Handa H, et al. The immobilization of a direct thrombin inhibitor to a polyurethane as a nonthrombogenic surface coating for extracorporeal circulation. J Mater Chem B 2016;4(13):2264-72.

102.Höfler L, Koley D, Wu J, et al. Electromodulated Release of Nitric Oxide Through Polymer Material from Reservoir of Inorganic Nitrite Salt. RSC Adv 2012;2:6765-7.

103. Ren H, Colletta A, Koley D, et al. Thromboresistant/antibiofilm catheters via electrochemically modulated nitric oxide release. Bioelectrochemistry 2015;104:10-6.

104. Mejaddam AY, Hornick MA, McGovern PE, et al. Erythropoietin Prevents Anemia and Transfusions in Extremely Premature Lambs Supported by an EXTrauterine Environment for Neonatal Development (EXTEND). Fetal Diagn Ther 2019;46:231-7.

105. Bertholdt C, Menard S, Delorme P, et al. Intraoperative adverse events associated with extremely preterm cesarean deliveries. Acta Obstet Gynecol Scand 2018;97:608-14.

106.Lannon SM, Guthrie KA, Vanderhoeven JP, et al. Uterine rupture risk after periviable cesarean delivery. Obstet Gynecol 2015;125:1095-100.

107.McLeod JS, Menon A, Matusko N, et al. Comparing mortality risk models in VLBW and preterm infants: systematic review and meta-analysis. J Perinatol 2020;40:695-703.

108. Sotodate G, Oyama K, Matsumoto A, et al. Predictive ability of neonatal illness severity scores for early death in extremely premature infants. J Matern Fetal Neonatal Med 2020. [Epub ahead of print].

109. Extremely Preterm Birth Outcomes Tool [Internet]. National Institutes of Health Eunice Kennedy Shriver National Institute of Child Health and Human Development 2020 [cited 3/4/2020]. Available online: https://www.nichd.nih.gov/research/supported/EPBO/use. 